\title{
Supporting Information of
}

\section{Using AMBER18 for Relative Free Energy Calculations}

Lin Frank Song ${ }^{a}$, Tai-Sung Lee ${ }^{b}$, Chun-Zhu ${ }^{a}$, Darrin M. York ${ }^{b}$, and Kenneth M. Merz Jr. ${ }^{a, c}$

a. Department of Chemistry and the Department of Biochemistry and Molecular Biology, Michigan State University, 578 S. Shaw Lane, East Lansing, MI 48824

b. Laboratory for Biomolecular Simulation Research, Institute for Quantitative Biomedicine and Department of Chemistry and Chemical Biology, Rutgers University, Piscataway, New Jersey 08854, United States

c. Institute for Cyber Enabled Research, Michigan State University, 567 Wilson Road, Room 1440, East Lansing, MI 48824

Corresponding author: Kenneth M. Merz Jr.

Phone: (517) 355-9715

Fax: (517) 353-7248

E-mail: kmerz1@gmail.com 
SI Table 1. Summary of the MUE and RMSD of the eight systems based on $\triangle \triangle \mathrm{G}$ values directly obtained from FEP or TI calculations.

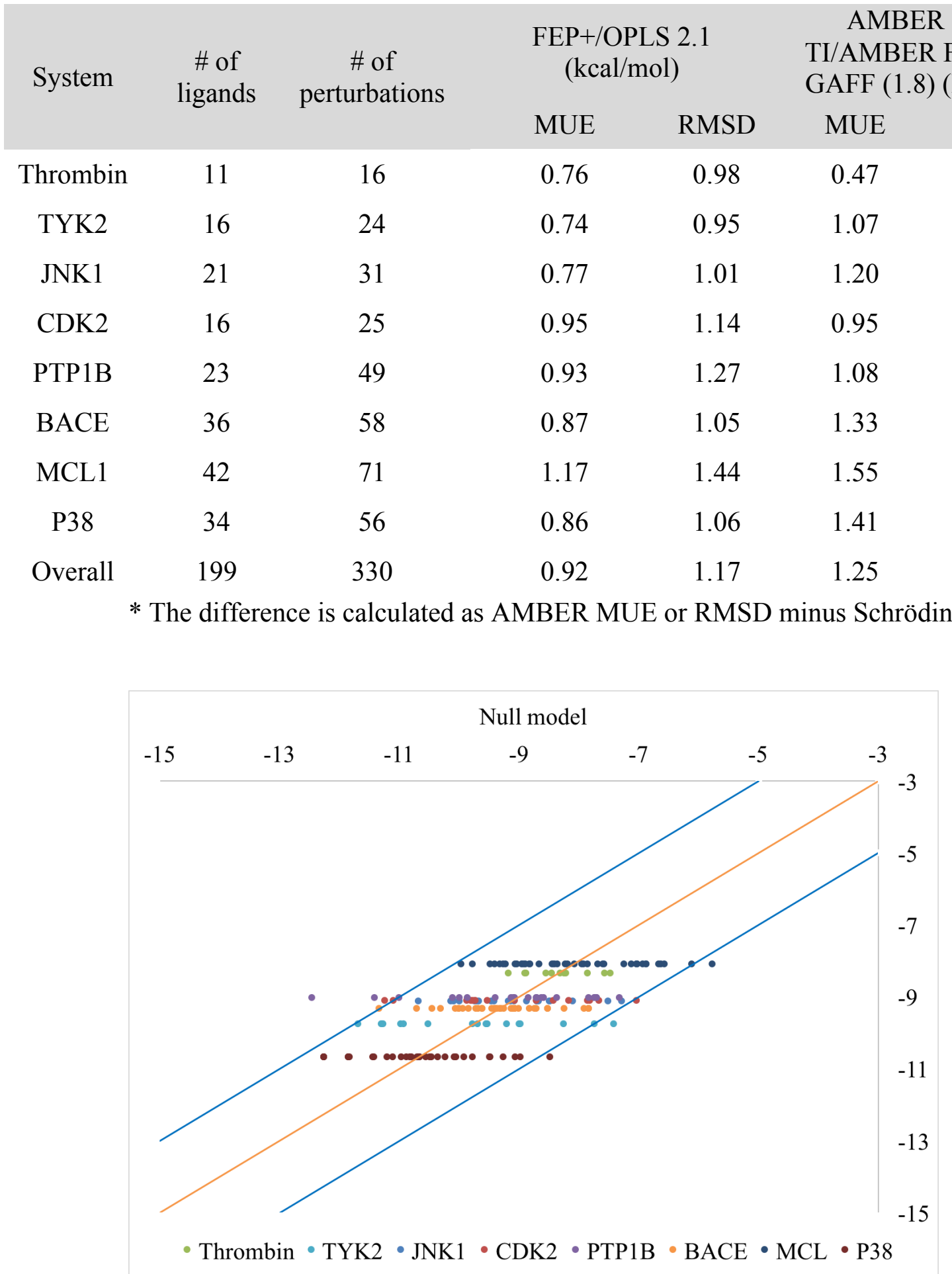

SI Figure 1: Correlation between predicted binding free energies and experimental values for a null model, which has all the $\Delta \Delta \mathrm{G}$ set to $0 \mathrm{kcal} / \mathrm{mol}$. X axis: Experimental $\Delta \mathrm{G}(\mathrm{kcal} / \mathrm{mol}) ; \mathrm{Y}$ axis: Predicted $\Delta \mathrm{G}(\mathrm{kcal} / \mathrm{mol})$. 